\title{
Effects of Lateral and Vertical Constrictions on Flow in Rough Steep Channels with Bedload
}

\author{
S. Schwindt ${ }^{1}$; M. J. Franca ${ }^{2}$; and A. J. Schleiss, M.ASCE ${ }^{3}$
}

\begin{abstract}
Two-phase flows occurring at flow constrictions such as bridges or open sediment check dams are complex, especially for steep rivers with bedload transport. Dangerous bedload deposition and backwater effects may occur in steep mountain rivers at bridges. In contrast, sediment deposition is desirable at open check dams combined with sediment traps. For design purposes, the discharge and bedload capacity across these flow constrictions must be known. The energy losses, discharge capacity, and bedload transport capacity of vertical and lateral flow constrictions are experimentally studied in a rough, $2 \%$ inclined, trapezoidal channel. Both free surface and pressurized flow conditions, as caused by lateral and vertical flow constrictions, respectively, were analyzed because both may occur at bridges and check dams. The experiments demonstrate that the vertical flow constrictions cause a faster increase in the backwater depth, with increasing discharge, than lateral constrictions. The resulting upstream flow conditions can be described by the upstream Froude number, defined as a function of the constriction dimensions (height and width). The bedload transport capacity through the flow constriction decreases with the upstream Froude number. The practical relevance of the findings is illustrated by a design example of flow constrictions at open sediment check dams.
\end{abstract} DOI: 10.1061/(ASCE)HY.1943-7900.0001389. ( 2017 American Society of Civil Engineers.

Author keywords: Open sediment check dams; Bedload; Flow-structure interactions; Mountain rivers; Rough channels.

\section{Introduction}

A major part of sediment transported along mountain rivers is in the form of bedload. This generally depends on the sediment supply, in terms of grain size and volume, as well as on the transport capacity, which is here considered in terms of the discharge and channel flow properties (Recking 2012). The flow properties depend on the channel roughness, geometry, and slope. Consequently, the bedload transport in headwaters can be limited because of either the sediment supply or the transport capacity of the channel.

Flood discharges with a high transport capacity can erode instream-stored sediment of steep headwaters (Sawada et al. 1983; Whittaker 1987) and also supplied sediment from external sources such as debris flow (Beschta 1979; Benda 1990). The eroded sediment is then conveyed to milder-sloped and wider downstream reaches (e.g., Montgomery and Buffington 1997), typically characterized by alluvial fans, where the coarser fraction (bedload) deposits (Sutherland et al. 2002; Hassan et al. 2005). Such alluvial fans may originate from the deposition of constantly transported sediment, sheet flows, or debris flows (Parker et al. 1998).

Nowadays, alluvial fans are often occupied by settlements, and exhaustive sediment deposition in these areas can cause serious damage [e.g., as occurred in Switzerland in 2005 (Bezzola and Hegg 2007)]. Such undesired sediment deposition can be prevented

${ }^{1}$ Research Assistant, Laboratoire de constructions hydrauliques, École polytechnique fédérale de Lausanne, Station 18, 1015 Lausanne, Switzerland (corresponding author). E-mail: sebastian.schwindt@epfl.ch

${ }^{2}$ Research and Teaching Associate, Laboratoire de constructions hydrauliques, École polytechnique fédérale de Lausanne, Station 18, 1015 Lausanne, Switzerland.

${ }^{3}$ Full Professor, Laboratoire de constructions hydrauliques, École polytechnique fédérale de Lausanne, Station 18, 1015 Lausanne, Switzerland.

Note. This manuscript was submitted on August 22, 2016; approved on June 23, 2017; published online on October 12, 2017. Discussion period open until March 12, 2018; separate discussions must be submitted for individual papers. This paper is part of the Journal of Hydraulic Engineering, (C) ASCE, ISSN 0733-9429. by installing sediment traps immediately upstream of urban areas (Armanini et al. 1991). A key element of such sediment traps is an open sediment check dam; that is, a massive barrier with one or more openings to control the flow (Piton et al. 2017). The size and geometry of the opening(s) of the sediment check dam are decisive for sediment retention, which can be caused by two obstruction mechanisms (Piton and Recking 2016a): (1) mechanical obstruction because of the size of the solids transported by the river; and (2) hydraulic obstruction, which occurs when the discharge capacity of the constriction is exceeded. The results of numerous studies on mechanical obstruction are summarized by Piton and Recking (2016a). Hydraulic obstruction was studied, among others, by Armanini and Larcher (2001) and Armanini et al. (2006). In both cases, backwater occurs, and the generally supercritical flow in mountain rivers becomes subcritical, thereby triggering sediment deposition.

However, sediment check dams often interrupt sediment transport and, therefore, natural stream dynamics (Gomi et al. 2002; Adams and Spotila 2005; Davies et al. 2005). The resulting lack of sediment has negative effects on the stream's ecology (LeRoy et al. 1997) and reduces morphological diversity (Williams and Wolman 1984; Kondolf 1997). Therefore, open sediment check dams need to be designed to retain bedload only for floods that are hazardous to the downstream valley, allowing, however, sediment continuity for floods with lower magnitude (Schleiss et al. 2014).

At open check dams with free surface flow, a lateral flow constriction provokes a critical section (Armanini and Larcher 2001; Piton and Recking 2016a). Similar lateral flow constrictions also can be observed at bridges if the water level is lower than the vertical clearance height underneath the bridge. Open check dams with a closed crest represent a vertical flow constriction resulting in pressurized orifice flow (Piton and Recking 2016a). Pressurized flow also may occur during floods at bridges, which may cause unwanted overtopping of the bridge and its abutments (McEnroe 2009). In addition, open check dams or bridges may comprise combined lateral and vertical constrictions. 
To the best of the authors' knowledge, systematic studies of the hydrodynamics coupled with the bedload transport at such flow constrictions are lacking. Therefore, energy losses, discharge capacity, and bedload transport capacity of vertical, lateral, and combined flow constrictions are systematically analyzed in this study. A moderately steep, rough channel with a $2 \%$ bottom slope was used, which reproduces typical conditions of channels on alluvial fans formed by constant sediment supply (Montgomery et al. 1996; Parker et al. 1998). The effects of flow constrictions on the bedload transport capacity of this type of channel are analyzed in terms of the critical bed shear stress and considering the sediment supply at equilibrium transport capacity. With a fixed bed, morphological channel adjustments upstream of check dams are not considered. The problem of the combined trapping of floating objects and bedload, studied by Uchiogi et al. (1996), Lange and Bezzola (2006), and Piton and Recking (2016b), among others, is not considered here either.

\section{Theoretical Discharge Capacity of Flow Constrictions}

To estimate the discharge capacity of the flow constrictions, two flow situations are considered at the constriction, given that the constriction imposes a hydraulic jump upstream (transition from supercritical to subcritical flow):

- Orifice discharge under pressurized flow conditions (vertical and combined constriction)

- Free surface critical flow (lateral constriction)

The flow situations at vertical, lateral, and combined flow constrictions are illustrated in Fig. 1, where $a=$ constriction height; $b=$ constriction width; $w=$ bottom width of the channel; $m=$ channel bank slope; $h_{0}$ and $H_{0}=$ upstream uniform flow depth and energy head, respectively; $u_{0}^{2} /(2 g)=$ upstream velocity head; $h_{c r}=$ critical flow depth; $u=$ cross-averaged flow velocity (in $\mathrm{m} / \mathrm{s}$ ); and $g=$ gravity acceleration (in $\mathrm{m} / \mathrm{s}^{2}$ ). The discharge capacity needs to be evaluated separately for pressurized and free surface flow conditions, which are introduced subsequently.

The discharge capacity of pressurized flow constrictions is based on a Torricelli-type formulation for the calculation of the velocity (i.e., $u=\sqrt{2 g h}$, where $h=$ generic flow depth, here corresponding to the flow depth upstream of the constriction). Subsequently, it is assumed that the pressure distribution is hydrostatic over the opening height. The approaching flow velocity is nonnegligible; hence, the kinetic energy is also nonnegligible in the total energy balance. Therefore, the flow depth $h$ is substituted by the energy head $H$ (Chow 1959).

The pressure flow in combined constrictions requires the decomposition of the cross-section geometry in a trapezoidal bottom part and an upper rectangular part [Fig. 1(b)]. For vertical flow constrictions, only the trapezoidal part is relevant [Fig. 1(a)]. The parameter $H_{t}$ accounts for the head above the trapezoidal part of the opening. In the case of solely vertical constrictions, $H_{t}=$ $H_{0}-a$. For composed cross sections (the trapezoidal and rectangular part), $H_{t}=H_{0}-(b-w) /(2 m)$ [Figs. 1(b and c)].

Integrating the flow velocity over the opening surface, according to Torricelli's velocity distribution, results in the following expression for the discharge capacity $Q_{c}$, which is only valid for pressurized flow constrictions $\left(h_{0}-a>0\right)$ :

$$
\begin{aligned}
Q_{c}= & \mu \sqrt{2 g} \cdot[\overbrace{\frac{2 w\left(H_{0}^{1.5}-H_{t}^{1.5}\right)}{3}+\overbrace{2}^{\frac{H_{0}}{3} \cdot(b-w) \cdot\left(H_{0}^{1.5}-H_{t}^{1.5}\right)}}^{\text {center of trapeze }} \text { wings of trapeze } \\
& +\overbrace{-\frac{2}{5} \cdot \frac{b-w}{H_{0}-H_{t}}\left(H_{0}^{2.5}-H_{t}^{2.5}\right)}^{\text {wings of trapeze }}+\overbrace{\frac{2}{3} b\left(H_{t}^{1.5}-\left(H_{0}-a\right)^{1.5}\right)}^{\text {top rectangle }}]
\end{aligned}
$$

The derivation of Eq. (1) considers the effects of the vena contracta and local energy losses in terms of the discharge coefficient $\mu$. Von Mises (1917) and Werner (1963) developed a theoretical approach based on streamlines to evaluate the losses because of the vena contracta as a function of the upstream flow depth, the downstream flow depth, and the opening height. The experiments conducted by Brooke Benjamin (1956) show that this procedure is accurate for smooth wall conditions. This approach is not suitable for rough flow with bedload such as in the application considered herein. According to Leys (1976), the corresponding inaccuracies are typically accounted for as $\mu \in[0.6,0.7]$. The experimental data from Mejean et al. (2015) confirm this interval. The evaluation of the discharge coefficient $\mu$ is further developed in this paper for turbulent and rough flow with bedload.

A simplification of Eq. (1) applies for purely rectangular flow cross sections $\left(H_{t}=H_{0}\right.$ and $\left.w=b\right)$ :

$$
Q_{c, \text { rect }}=2 / 3 \cdot \mu \cdot b \cdot \sqrt{2 g} \cdot\left[H_{0}^{\frac{3}{2}}-\left(H_{0}-a\right)^{\frac{3}{2}}\right]
$$

Leys (1976) and Zollinger (1983) also applied Eq. (1) for free surface flow in lateral flow constrictions. This is questionable because Eq. (1) is based on the assumption of a hydrostatic pressure distribution, which is an approximation that is acceptable only for pressurized flow conditions. In the case of free surface flow [lateral constrictions, Fig. 1(c)], the energy balance according to Armanini and Larcher (2001) can be applied for the derivation of the discharge capacity. These authors equate the total energy per unit weight upstream of the constriction and in the constriction. Because the constriction is a control section, the Froude number equals unity here, and the equation can be solved for the discharge. In addition, this approach neglects the upstream flow velocity, which needs to be considered here, as mentioned previously. The application of the energy balance upstream of the constriction and the control section

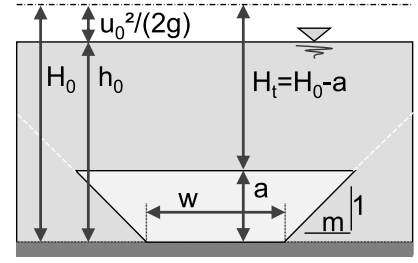

(a)

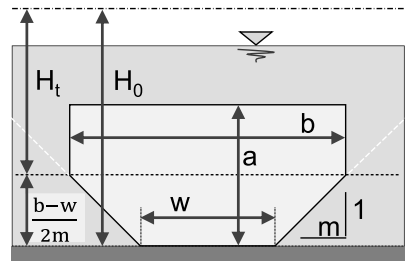

(b)

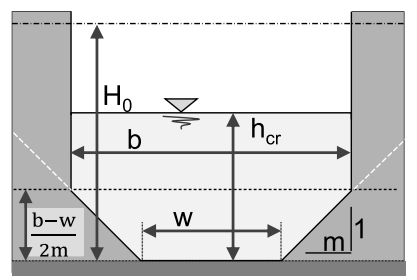

(c)

Fig. 1. Flow cross sections of the constriction types considered: (a) vertical (i.e., trapezoidal) with pressurized flow conditions; (b) combination of vertical and lateral with pressurized flow conditions; (c) lateral only with free surface flow 
in a constriction with a trapezoidal or composed flow cross section, with consideration of the approach velocity, results in

$$
Q_{c}=\sqrt{2 g \cdot\left(h_{c r}-h_{0}\right) \cdot\left(\frac{1}{A_{0}^{2}}-\frac{1}{A_{c r}^{2}}\right)^{-1}}
$$

The trapezoidal cross section is computed by $A=w h+h^{2} m$. For the cross sections of the upstream channel $A_{0}$ and the flow constriction, $h$ is replaced by $h_{0}$ and $h_{c r}$, respectively. The approach neglects several local losses at the flow constriction because of three-dimensional (3D) flow effects, as well as the geometry of the constriction walls. The required correction of Eq. (3) is subsequently considered by a factor $\epsilon$, defined as the ratio of observed and calculated discharge:

$$
\epsilon=\frac{Q_{\text {obs. }}}{Q_{c}(\text { Eq. 3) }}
$$

The critical flow depth $h_{c r}$ in the constriction is calculated by equating the Froude number to unity. A further simplification of Eq. (3) is possible in the case of rectangular lateral constrictions, where the upstream head $H_{0}$ equals approximately $1.5 \cdot h_{c r}$ (Armanini and Larcher 2001).

\section{Methodology}

\section{Experimental Setup}

The experimental setup (Fig. 2), including the channel geometry and the grain size distribution, was designed based on 131 field observations from torrents in the Alps and the Rocky Mountains, partially equipped with sediment check dams (e.g., Leopold and Wolman 1957; Gertsch 2009; Recking 2010).

The laboratory channel is divided into two reaches: a 2.5-m-long upstream adaptation reach, where sediment and water discharges are mixed, and a 3-m-long testing reach downstream, where the flow constrictions are situated. Both reaches have an equivalent roughness with a similar trapezoidal cross section, characterized by a channel base width of $w=0.11 \pm 0.02 \mathrm{~m}$ and a bank slope of $23.9^{\circ} \pm 0.9^{\circ}$. The longitudinal channel slope is $J_{0} \approx 2 \%$. The water discharge $Q$ is provided by the laboratory pumping system and varies between 5.5 and $10.0 \mathrm{l} / \mathrm{s}$. The sediment is stored in a cylindrical container with a perforated screw at its bottom. It supplies wet sediments on a system of conveyor belts that transport the sediment into the channel. The sediment supply

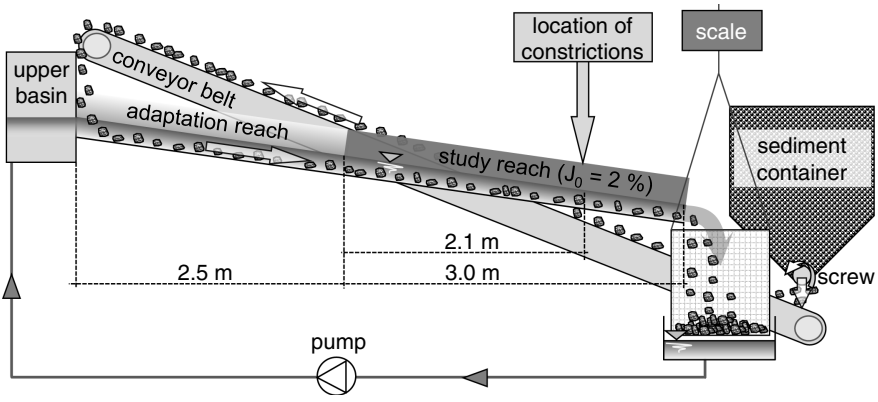

Fig. 2. Illustration of the experimental setup (longitudinal cross section), indicating the water supply by the laboratory pump system, the sediment supply structure, which consists of a cylindrical container with a perforated screw at the bottom and a conveyor belt, as well as the channel, with an upstream adaptation reach and a downstream study reach mixture for bedload $Q_{b}$ is characterized by the following parameters: $D_{10}=6 \mathrm{~mm}, D_{m}=9 \mathrm{~mm}, D_{84}=13 \mathrm{~mm}$, and $D_{\max }=21 \mathrm{~mm}$, where $D=$ grain diameter, of which the \#\% of the mixture is smaller; and $D_{m}=$ mean grain size of the mixture. The channel bed is made of wood planks with concrete-cast grains at the channel bed, with a characteristic diameter that is larger than the $D_{84}$ of the sediment supply mixture to confer roughness.

According to the field data, the geometric scale of the experimental setup is in a range between 1:10 and 1:40.

The channel constriction is introduced and varied in terms of the opening height $a$ and width $b$ by mobile PVC elements, as illustrated in Fig. 3. The opening dimensions can be regulated through increments of approximately $0.001 \mathrm{~m}$ in height and $0.025 \mathrm{~m}$ in width.

The flow depth is measured by ultrasonic probes (with a precision of $1 \mathrm{~mm}$ ) at four positions upstream and one position downstream of the constriction spaced approximately $0.5 \mathrm{~m}$ apart (denser at the constriction). The bedload is measured at the channel outlet by an industrial scale (precision, $0.1 \%$ ) suspended at a filter basket. The deposition of grains at low discharges is evaluated with an underwater camera. The pump discharge is recorded every $3 \mathrm{sec}$ onds by an electromagnetic flow meter (with a precision of $0.1 \%$ ).

The discharge and flow depth measurements made in the nonconstricted and constricted channels are used to estimate the hydraulic energy losses because of roughness, bedload, and flow constrictions, as well as to evaluate the discharge capacity of the constrictions.

\section{Experimental Data Evaluation and Procedures}

\section{Head Losses}

For the evaluation of energy losses because of constriction, the energy balance is set in terms of the cross-section-averaged energy per unit weight, which applies for a one-dimensional (1D) uniform distribution of flow velocity across the section, and on the assumption of a hydrostatic pressure distribution. Section 0 is located just upstream of the flow constriction and section 1 downstream of the flow constriction (cf. Fig. 4). Moreover, Fig. 4 shows qualitatively

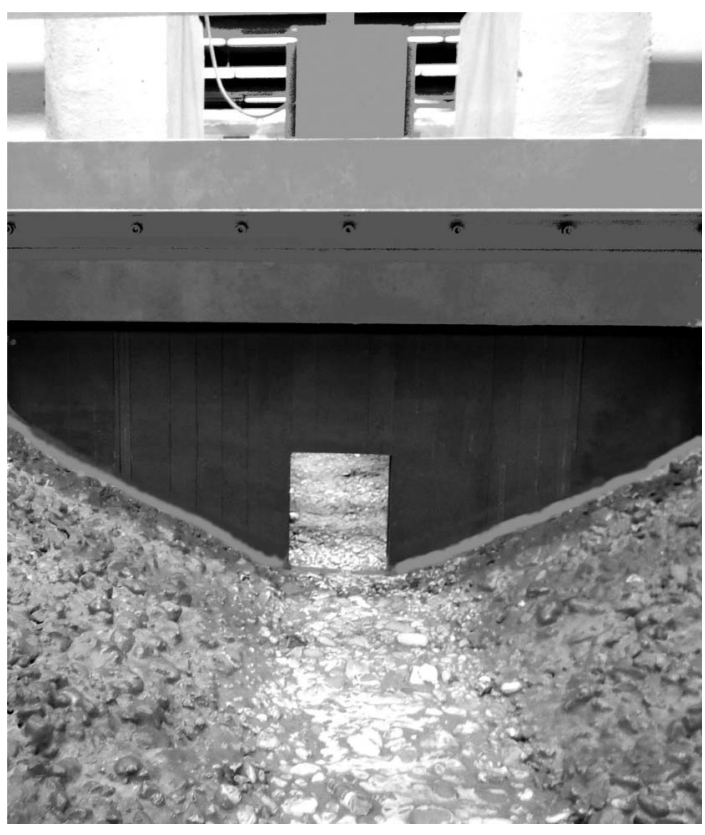

Fig. 3. Picture of the channel with constriction composed of multiple PVC elements (view from upstream to downstream) 


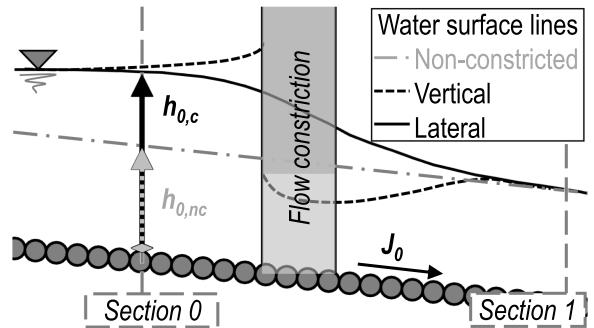

Fig. 4. Sketch of the longitudinal section at the flow constriction with the reference sections 0 (upstream) and 1 (downstream); the water levels and the flow depths $h_{0, n c}$ (nonconstricted channel) and $h_{0, c}$ (constricted channel) are qualitatively indicated; $J_{0}$ is the channel slope

the flow depths in the nonconstricted $h_{0, n c}$ and the constricted $h_{0, c}$ channel at section 0 .

The energy balance between sections 0 and 1 , therefore, is

$$
E_{0}=E_{1}+\Delta E_{r}+\Delta E_{Q_{b}}+\Delta E_{c}
$$

The energy losses correspond to the sum of losses because of the channel roughness $\Delta E_{r}$, losses because of bedload movement $\Delta E_{Q_{b}}$ (if present), and losses because of flow constrictions $\Delta E_{c}$ (if present). The laboratory flume is rectilinear, and the roughness losses are dominated by the bed grain friction because no relevant bed forms are allowed in the experiments. $\Delta E_{r}$ is evaluated in the nonconstricted channel without sediment supply using the Chézy roughness coefficient $C$ (in $\mathrm{m}^{1 / 2} \mathrm{~s}^{-1}$ ) according to Eq. (6), where $\Delta x=$ length between sections 0 and 1 :

$$
\Delta E_{r}=\Delta x \cdot J_{e}=\Delta x \cdot u_{0}^{2} \cdot C^{-2} \cdot R_{h 0}^{-1}
$$

where $u_{0}$ and $R_{h 0}=$ flow velocity and the hydraulic radius at section 0 , respectively. $C$ is estimated by applying a $1 \mathrm{D}$ numerical code that solves the $1 \mathrm{D}$ cross-section-averaged shallow water equation for the flow depth based on a Newton-Raphson scheme. The calculation of the continuous head loss is based on the hypothesis of quasiuniform flow conditions. The simulated values are compared with the data measured along the channel, and a global Chézy roughness coefficient $C$ is calibrated using a shooting method (Chapra and Canale 2010).

According to the literature, the losses because of bedload are $\Delta E_{Q_{b}}=D_{84} \cdot 1.25 \pm 0.25$ (Uchiogi et al. 1996; Frey et al. 1999; Piton and Recking 2016a). The constriction losses $\Delta E_{c}$ depend on the constriction dimension $(a, b)$ and are evaluated in terms of the local loss coefficient $\zeta_{c}$ :

$$
\Delta E_{c}=\zeta_{c} \cdot \frac{Q^{2}}{2 g A_{0}^{2}}
$$

Further energy losses, as listed by Piton and Recking (2016a), may occur because of the deposition height in front of the constriction or because of woody debris. Both sediment deposition and driftwood are not considered in this study.

\section{Discharge Capacity}

The discharge capacity is evaluated according to Eqs. (1) and (3) for pressurized and free surface flow conditions using the discharge coefficient $\mu$ and the correction factor $\epsilon$ of Eq. (3), respectively. $\mu$ and $\epsilon$ are evaluated within the range of the discharges tested without and with bedload.

\section{Bedload Transport Capacity}

The bedload transport capacity $Q_{b}$ is the maximum solid discharge that can be conveyed through the nonconstricted or the constricted
Table 1. Number of Measurements from the Nonconstricted and Constricted Channel $(\Sigma=368)$

\begin{tabular}{lcc}
\hline Constriction type & Without bedload & With bedload \\
\hline None & 63 & 34 \\
Vertical only & 37 & 30 \\
Lateral only & 74 & 32 \\
Combined & 49 & 49 \\
\hline
\end{tabular}

channel for a given discharge. This capacity corresponds to the outflowing sediment weight measured with the suspended basket. The wet, nonsubmerged sediment is weighed every minute, outside the outflowing water jet. The evaluation procedure is repeated for the nonconstricted and constricted channels for each geometric configuration of the constriction and for increasing discharge from 5.5 to $10.0 \mathrm{l} / \mathrm{s}$, by $0.3 \mathrm{l} / \mathrm{s}$ steps (approximately). The procedure begins with a low sediment supply, which is incrementally increased until the first deposits occur in the channel. The highest sediment supply without sediment deposition in the channel is considered subsequently as the hydraulic bedload transport capacity $Q_{b}(Q)$ for the discharge in question. A total of 368 data sets were obtained, as listed in Table 1 . The bed shear stress $\tau_{0}$ corresponding to the bedload transport capacity is derived from the flow depth and discharge measurements. $\tau_{0}$ is determined first for the nonconstricted channel and then for each setup of lateral, vertical, and combined flow constrictions by

$$
\tau_{0}=\rho_{f} \cdot g \cdot J_{e} \cdot R_{h}
$$

where $\rho_{f}=$ fluid density $(1,000 \mathrm{~kg} / \mathrm{m})$. The energy slope is computed by $J_{e}=u /\left(C 2 \cdot R_{h}\right)$, where $R_{h}=$ hydraulic radius (m), based on the water depth $h$, the channel bottom width $w$, and the bank slope $m$ (Fig. 1).

\section{Parameters and Dimensional Analysis}

The hydraulic conditions at the flow constriction are assessed by the energy balance [Eq. (5)], which implies the following 17 parameters (here defined generically by the set of variables $\Lambda$ )

$\Lambda=f\left(a, b, D_{m}, g, H_{0}, h_{0, c}, h_{0, n c} J_{0}, J_{e}, m, q, q_{b}, w, \nu, \rho_{f}, \rho_{s}, \tau_{0}\right)$

$J_{0}=$ channel slope (dimensionless); $\nu=$ kinematic viscosity of water (in $\mathrm{m}^{2} / \mathrm{s}$ ); and $\rho_{s}=$ grain density $\left(2,680 \mathrm{~kg} / \mathrm{m}^{3}\right)$. The flow depth is differentiated between the nonconstricted channel $h_{0, n c}$ and the constricted channel $h_{0, c}$ (cf. Fig. 4), and $q$ and $q_{b}$ are the discharge and bedload transport capacity per unit width. Because $\tau_{0}$ [Eq. (8)] and $H_{0}$ are derived from the remaining variables, the system reduces to 15 parameters.

The dimensionless analysis is conducted according to the П-theorem (Barenblatt 1987). All parameters stated in Eq. (9) are defined by three dimensions: mass $M$, length $L$, and time $T$. Therefore, a dimensional matrix of rank $\Re=3$ is established for deriving $15-3=12 \Pi$-groups by applying $h_{0, n c}, g$, and $\rho_{f}$ as repeating and linearly independent variables. $h_{0, n c}$ is the discharge-related flow depth of the nonconstricted flow at section 0 . This leads to the following dimensionless expression:

$$
\begin{aligned}
\Pi_{\Lambda}= & f\left(\frac{a}{h_{0, n c}}, \frac{b}{h_{0, n c}}, \frac{D_{m}}{h_{0, n c}}, \frac{h_{0, c}}{h_{0, n c}}, J_{0}, J_{e}, m, \frac{q}{h_{0, n c}^{\frac{3}{2}} g^{\frac{1}{2}}},\right. \\
& \left.\frac{q_{b}}{h_{0, n c}^{\frac{3}{2}} g^{\frac{1}{2}} \rho_{f}}, \frac{w}{h_{0, n c}}, \frac{\nu}{h_{0, n c}^{\frac{3}{2}} g^{\frac{1}{2}}}, \frac{\rho_{s}}{\rho_{f}}\right)
\end{aligned}
$$


This analysis aims at the characterization of the interactions between the constriction dimensions, $a$ and $b$, and the flow in terms of (unitary) discharge $q$, flow depth $h_{0}$, and energy slope $J_{e}$. Hence, only these parameters are considered in the subsequent analysis. Rearranging the relevant $\Pi$-numbers results in the following dimensionless numbers:

- Backwater ratio $h_{*}=\left(h_{0, c} / h_{0, n c}\right)^{-1}$, where $h_{0, n c}=$ uniform flow depth (nonconstricted channel), and $h_{0, c}=$ backwater depth upstream of the constriction;

- Froude number $\mathrm{F}=Q \cdot \sqrt{\left(w+2 h_{0} m\right) /\left(A_{0}^{3} \cdot g\right)}$;

- Constriction height ratio $a_{*}=a / h_{0, n c}$;

- Constriction width ratio $b_{*}=b /\left(w+2 h_{0, n c} m\right)$; and

- Ratio of bed shear stress reduction $\eta=\tau_{0, c} / \tau_{0, n c}=$ $R_{h 0, c} \cdot J_{e 0, c} / R_{h 0, n c} \cdot J_{e 0, n c}$.

Combined vertical and lateral constrictions are represented by the product of the dimensionless numbers $a_{*}$ and $b_{*}$. Variables related to the constricted and nonconstricted channel are indexed with subscripts $c$ and $n c$, respectively. The index 0 refers to the flow cross section immediately upstream of the constriction.

The reduction in the hydraulic bedload transport capacity is analyzed with the ratio of the bed shear stress $\tau_{0}$ in the constricted and the nonconstricted channels, $\eta=\tau_{0, c} / \tau_{0, n c}$.

In addition, the discharge capacity of flow constrictions is analyzed using Eqs. (1) and (3).

\section{Results and Analysis}

\section{Energy Losses in the Nonconstricted Channel}

The energy losses because of roughness are derived based on the cross-section-averaged flow velocity $u$, in terms of the Chézy roughness coefficient [see Eq. (6)]. The resulting relationship between the discharge and reach-averaged roughness coefficient $C$ is shown in Fig. 5 for the flow without and with bedload. The deviation of $C$ of the reach-average (Fig. 5) is approximately $23 \%$ for each discharge.

The roughness-induced energy losses $\Delta E_{r}$, as introduced in Eq. (5), are determined according to Eq. (6), where $\Delta x$ denotes the length between sections 0 and 1 . The effect of bedload is evaluated by comparing the energy losses in terms of roughness without and with bedload. When bedload is present, the average Chézy coefficient $C$ is reduced by a factor of 0.985 . This observation may be impacted by the fact that the bedload represents an additional volume that increases the flow depth. However, the bedload transport capacity in the present experiments is only approximately $0.05-0.5 \%$ of the total discharge and has no measurable effect on the flow depth. Therefore, compared to other studies where sediment deposits were considered (Uchiogi et al. 1996; Frey et al. 1999; Piton and Recking 2016a), the influence of bedload in the global head loss is negligible here (i.e., $\Delta E_{Q_{b}} \approx 0$ ).

\section{Effect of Flow Constrictions on the Upstream Flow}

The dimensionless backwater ratio $h_{*}$, provided by the dimensional analysis, is defined by the ratio between the uniform flow depth $h_{0, n c}$ and the backwater depth $h_{0, c}$ immediately upstream of the constriction (Fig. 4). The measured backwater ratio $h_{*}$ and upstream Froude number $F_{0}$, as a function of the constriction ratios $a_{*}$ and $b_{*}$, are shown in Figs. 6(a and b), respectively. Data sets without bedload are indicated by open symbols, and those with bedload are indicated by filled symbols.

The flow conditions upstream are more adequately described by the upstream Froude number $F_{0}$. The data may be grouped according to the constriction type (vertical, lateral, or combined). Then the relation between the constriction ratio and $h_{*}$ or $\mathrm{F}_{0}$ is clearly visible, as shown in Fig. 6. The regression curves (gray lines in Fig. 6) can be derived based on

$$
f(\Phi)=p_{1} \cdot \Phi^{p_{2}}+p_{3}
$$

For the regression curves indicated in Fig. $6, \Phi$ is replaced by the constriction ratio (vertical $a_{*}$, lateral $b_{*}$, or combined $a_{*} \cdot b_{*}$ ), and $f$ represents $h_{*}$ or $\mathrm{F}_{0}$. The coefficients $p_{1}, p_{2}$, and $p_{3}$ are empirical constants as defined in Table 2. Eq. (11) is the definition of a power law equation and is also applied here for the description of linear curves when $p_{2}=1$. The goodness of fit of the regression curves is measured using the coefficient of determination $R^{2}$, which accounts for the variation in the data, as shown for the individual graphs in Table 2.

Analog to the evaluation of the roughness coefficient, the results in Fig. 6 show that the presence of bedload has no significant influence on the flow conditions upstream of the constriction (backwater ratio $h_{*}$ and Froude number $\mathrm{F}_{0}$ ).

In the following discussion, the distinction between the three constriction types is only based on how they affect the upstream flow conditions in terms of $h_{*}$ and $\mathrm{F}_{0}$.

\section{Head Loss}

The energy balance [Eq. (5)] can be rewritten by setting the head loss because of the constriction $\Delta E_{c}$ equal to the head difference between the reference sections 0 and 1 and by subtracting the continuous loss $\Delta E_{r}$. The loss $\Delta E_{Q_{b}}$ because of bedload can be

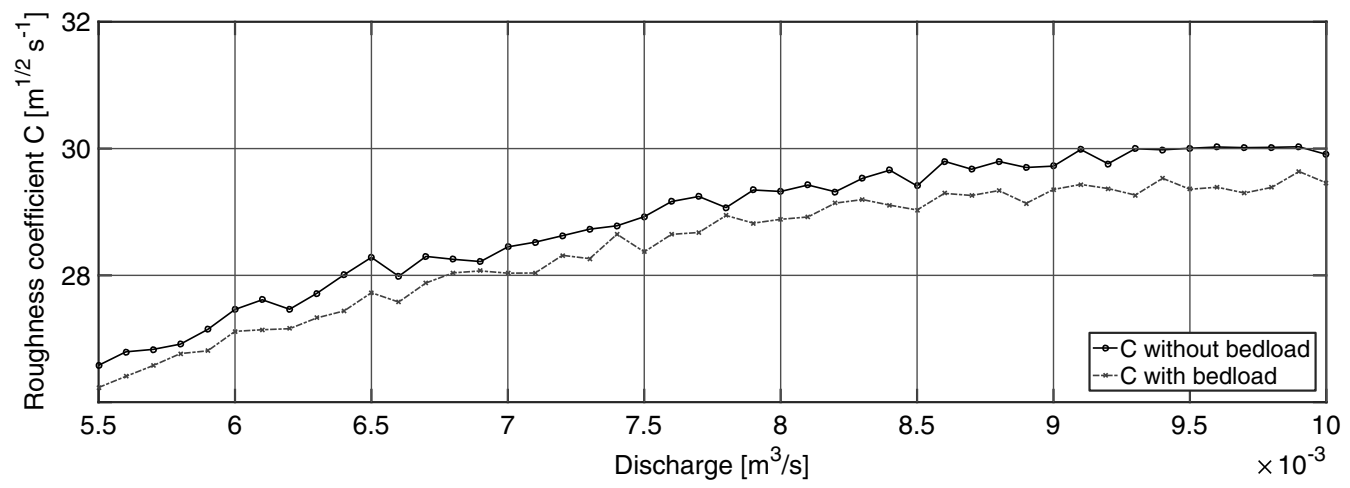

Fig. 5. Evaluation of the Chézy roughness coefficient $C$ as a function of discharge, without and with bedload (considering the increased discharge volume) 

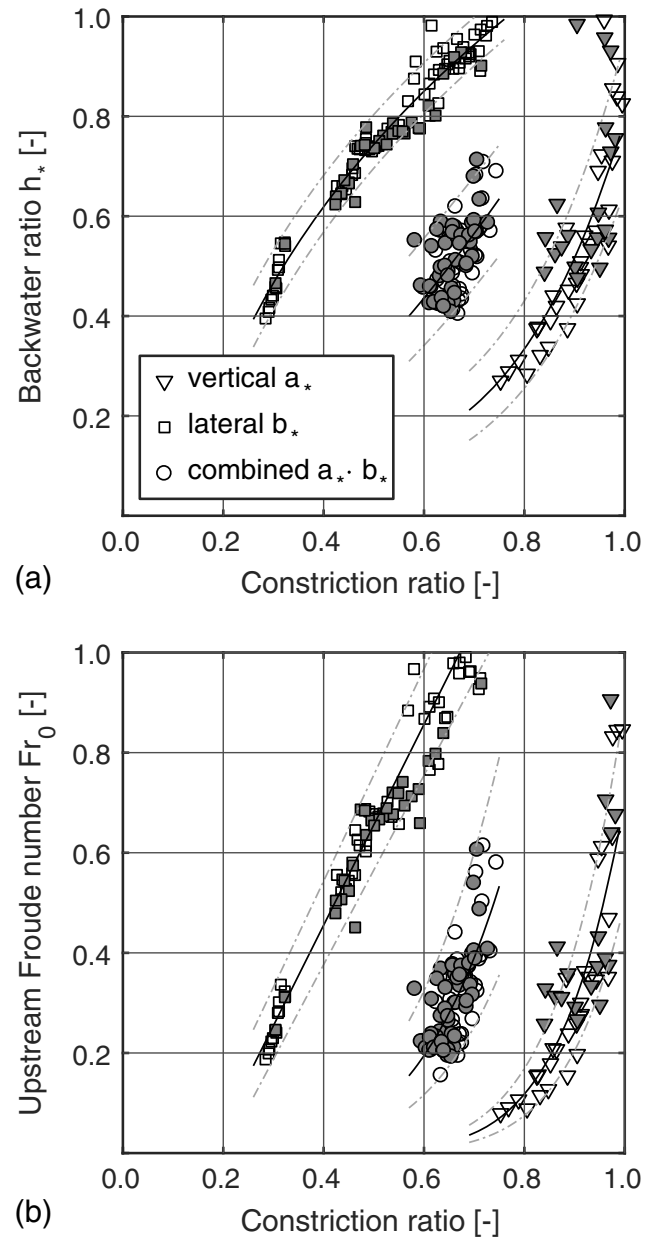

Fig. 6. Experimental values of (a) the backwater ratio $h_{*}$; (b) the Froude number $F_{0}$ as a function of the constriction ratio; the regression lines according to Eq. (11) and Table 2 are plotted; the dashed lines indicate the standard deviation (68\% confidence interval); the filled data points correspond to measurements with bedload

neglected, as mentioned previously. Based on Eqs. (5)-(7), the local loss coefficient $\zeta_{c}$ can be assessed with the experimental data

$$
\Delta E_{c}=E_{0}-E_{1}-\Delta E_{r}-\overbrace{\Delta E_{Q_{b}}}^{\approx 0}=\zeta_{c} \cdot \frac{Q^{2}}{2 g A_{0}^{2}}
$$

The loss coefficient $\zeta_{c}$ obtained is shown in Fig. 7 as a function of the backwater ratio $h_{*}$ and the Froude number upstream of the constriction $F_{0}$. The corresponding regression curves are based on Eq. (11), with the coefficients given in Table 2. It can be noted in Fig. 7 that the bedload has no significant effect on $\zeta_{c}$.

\section{Discharge Coefficient}

The discharge capacity of the vertical, pressurized flow constrictions can be computed by Eq. (1) using the discharge coefficient $\mu$. According to the literature, $\mu$ ranges from approximately 0.6-0.7 (Leys 1976; Zollinger 1983). In the present study, $\mu$ is calculated from the experimental data by substituting the geometrical and measured hydraulic quantities in Eq. (1). The values of $\mu$ obtained are represented in Fig. 8 as a function of the backwater ratio and upstream Froude number. The figures show a linear increasing trend of $\mu$ for low Froude numbers $(F<0.5)$ with well-developed backwater $\left(h_{*}<0.7\right)$. The linear regression curves indicated in
Fig. 8 are based on Eq. (11) with the coefficients listed in Table 2. For higher Froude numbers $(\mathrm{F}>0.5)$ and relatively small backwater $\left(h_{*}>0.7\right)$, the average of the discharge coefficient $\mu$ is approximately 0.69 with a standard deviation of \pm 0.08 .

Eq. (3) can be applied for lateral flow constrictions (free surface flow). The factor $\epsilon$ [Eq. (4)], which represents the ratio of the observed and computed discharge, is shown in Figs. 9(a and b) as a function of the constriction width ratio $b_{*}$ and the upstream Froude number $F_{0}$, respectively. In Figs. 9( $a$ and b), two cases can be clearly distinguished: (1) extensive backwater with rectangular cross sections, where $b_{*}$ and $\mathrm{F}_{0}$ are less than 0.4 ; and (2) limited backwater with trapezoidal cross sections.

In Case (1), $\epsilon$ increases linearly with rising backwater for both $b_{*}$ and $\mathrm{F}_{0}$. In Case (2), $\epsilon$ decreases linearly with rising backwater. The coefficients for the linear regression curves depend on $b_{*}$ and $\mathrm{F}_{0}$ according to Eq. (11) and are given in Table 2.

\section{Effect of Flow Constrictions on Bed Shear Stress}

In the constricted channel, the flow conditions just before the initiation of sediment deposition define the bedload transport capacity, as described in the experimental procedure. For these conditions, the value of the bed shear stress corresponding to the constricted channel $\left(\tau_{0, c}\right)$ is less than in the nonconstricted channel $\left(\tau_{0, n c}\right)$, as shown in Fig. 10 using the ratio of bed shear stresses $\eta$ as a function of the upstream Froude number $F_{0}$. The regression curve in Fig. 10 is described by Eq. (11), with the coefficients listed in Table 2. The corresponding coefficient of determination is close to unity, which demonstrates the good correlation between the upstream Froude number and $\eta$.

\section{Discussion}

\section{Roughness and Constriction Head Losses}

The continuous loss because of the roughness of the channel is determined using the Chézy equation [Eq. (6)]. According to Fig. 5, the channel roughness decreases with increasing discharge, which is in line with the literature (e.g., Chow 1959; Ferguson 2010; Powell 2014). Moreover, the Chézy coefficient increases slightly when bedload is supplied, which indicates an increase in the channel roughness. This increase seems to be related to the higher discharge because of bedload transport because the additional volume of the sediment increases the flow depth. The effect is small; however, it is expected to be more significant for steeper channels with slopes greater than 5\% (Smart and Jaeggi 1983). The total energy losses are then obtained by the sum of the losses because of roughness $\Delta E_{r}$ and because of the flow constrictions $\Delta E_{c}$ according to Eq. (5), where the bedload-induced energy losses are negligible $\left(\Delta E_{Q_{b}} \approx 0\right)$.

The constriction-induced loss coefficient $\zeta_{c}$ is shown in Fig. 7(a) as a function of the backwater ratio and in Fig. 7(b) as a function of the upstream Froude number. The loss coefficient $\zeta_{c}$ depends more on the upstream Froude number than on the backwater ratio, which is also reflected by the coefficients of determination of 0.95 and 0.65 , respectively.

\section{Flow Conditions Upstream of the Constriction}

The backwater effects as a function of the constriction ratios are analyzed in Fig. 6. A flow constriction causes deep backwater when the backwater ratio $h_{*}$ and upstream Froude number $\mathrm{F}_{0}$ tend toward zero. On the other hand, the constriction-induced backwater effects are small when $h_{*}$ and $\mathrm{F}_{0}$ are close to unity. 
Table 2. Empirical Coefficients $p_{1}, p_{2}$, and $p_{3}$ of the Regression Curves Shown in Figs. 6-10, according to Eq. (11), with the Observation Ranges Indicated

\begin{tabular}{|c|c|c|c|c|c|c|}
\hline Constriction type & $f(\Phi)$ & $\Phi \in$ [observation] & $p_{1}$ & $p_{2}$ & $p_{3}$ & $R^{2}$ \\
\hline \multicolumn{7}{|c|}{ Backwater ratio $h_{*}[$ Fig. 6(a)] } \\
\hline Vertical & $h_{*}\left(a_{*}\right)$ & $a_{*} \in[0.70,0.99]$ & 0.70 & 4.77 & 0.09 & 0.72 \\
\hline Lateral & $h_{*}\left(b_{*}\right)$ & $b_{*} \in[0.28,0.76]$ & 3.18 & 0.21 & -2.01 & 0.95 \\
\hline Combined & $h_{*}\left(a_{*}, b_{*}\right)$ & $a_{*} \cdot b_{*} \in[0.53,0.68]$ & 1.03 & 1.69 & 0 & 0.34 \\
\hline \multicolumn{7}{|c|}{ Upstream Froude number $F_{0}$ [Fig. 6(b)] } \\
\hline Vertical & $\mathrm{F}_{0}\left(a_{*}\right)$ & $a_{*} \in[0.70,0.99]$ & 0.71 & 8.04 & 0 & 0.82 \\
\hline Lateral & $\mathrm{F}_{0}\left(b_{*}\right)$ & $b_{*} \in[0.28,0.76]$ & 2.01 & 1.00 & -0.35 & 0.92 \\
\hline Combined & $\mathrm{F}_{*}\left(a_{*}, b_{*}\right)$ & $a_{*} \cdot b_{*} \in[0.53,0.68]$ & 1.96 & 4.52 & 0 & 0.48 \\
\hline \multicolumn{7}{|c|}{ Loss coefficient of constrictions $\zeta_{c}$ (Fig. 7) } \\
\hline Backwater ratio & $\zeta_{c}\left(h_{*}\right)$ & $h_{*} \in[0.38,0.99]$ & 0.20 & -2.50 & -0.12 & 0.65 \\
\hline Froude number & $\zeta_{c}\left(F_{0}\right)$ & $\mathrm{F}_{0} \in[0.17,0.96]$ & 0.51 & -0.86 & -0.46 & 0.95 \\
\hline \multicolumn{7}{|c|}{ Discharge coefficient $\mu$ (Fig. 8) } \\
\hline Backwater ratio & $\mu\left(h_{*}\right)$ & $h_{*} \in[0.70,0.99]$ & 0.39 & 1.00 & 0.40 & 0.64 \\
\hline Froude number & $\mu\left(\mathrm{F}_{0}\right)$ & $\mathrm{F}_{0} \in[0.50,0.96]$ & 0.38 & 1.00 & 0.48 & 0.60 \\
\hline \multicolumn{7}{|c|}{ Correction factor $\epsilon$ of Eq. (3) (Fig. 9) } \\
\hline Width ratio & $\epsilon\left(b_{*}<0.35\right)$ & $b_{*} \in[0.28,0.35]$ & 6.39 & 1.00 & -0.76 & 0.75 \\
\hline & $\epsilon\left(b_{*}>0.4\right)$ & $b_{*} \in[0.40,0.76]$ & -1.23 & 1.00 & 1.86 & 0.93 \\
\hline Froude number & $\epsilon\left(\mathrm{F}_{0}<0.3\right)$ & $\mathrm{F}_{0} \in[0.17,0.30]$ & 1.81 & 1.00 & 0.72 & 0.95 \\
\hline & $\epsilon\left(\mathrm{F}_{0}>0.44\right)$ & $\mathrm{F}_{0} \in[0.44,0.96]$ & -0.66 & 1.00 & 1.63 & 0.66 \\
\hline \multicolumn{7}{|c|}{ Ratio of bed shear stress $\eta$ (Fig. 10) } \\
\hline Froude number & $\eta\left(\mathrm{F}_{0}\right)$ & $\mathrm{F}_{0} \in[0.17,0.96]$ & 0.74 & 1.59 & 0.0 & 0.98 \\
\hline
\end{tabular}

In practice, the flow depth upstream of a constriction $h_{0, c}$ can be derived from Fig. 6(a) on the basis of the flow depth in the nonconstricted channel $h_{0, n c}$ and the constriction dimensions $a$ and $b$. For instance, the dimensionless constriction ratios $a_{*}$ and $b_{*}$ can be computed by dividing $a$ and $b$ by $h_{0, n c}$. Then, the corresponding backwater ratio $h_{*}$ can be deduced from the regression lines shown in Fig. 6(a). The value of $h_{*}$ obtained is defined as the ratio of the flow depths in the nonconstricted $h_{0, n c}$ and the constricted $h_{0, c}$ channel. Thus, the flow depth in the constricted channel can be assessed by the known value of $h_{0, n c}$ and the estimated value of $h_{*}: h_{0, c}=$ $h_{0, n c} / h_{*}$. A similar, discharge-based derivation of $h_{0, c}$ is possible using the upstream Froude number $F_{0}$ shown in Fig. 6(b).

The minimum and maximum values of $h_{*}$ and $\mathrm{F}_{0}$ correspond to the maximum and minimum discharges tested: 10.0 and $5.5 \mathrm{l} / \mathrm{s}$, respectively. All constriction types were tested within this same range of discharges. Therefore, the sensitivity of the backwater caused by a certain constriction type can be assessed within the experimental range of $h_{*}$ or $\mathrm{F}_{0}$.

For vertical constrictions, the reduction in the constriction height ratio $a_{*}$ causes a sharp and prominent decrease in $h_{*}$ [Fig. 6(a)], where the minimum and maximum discharges correspond to a 0.72 decrease in $h_{*}$. The insertion of a lateral constriction causes a smaller 0.59 reduction in $h_{*}$. An analogous observation can be made based on the upstream Froude number $F_{0}$ [Fig. 6(b)]. Within the range of discharges tested, the vertical constrictions cause a substantial 0.91 decrease in $\mathrm{F}_{0}$, while the lateral constrictions cause a smaller 0.80 decrease in $F_{0}$. These numbers reveal that the development of backwater because of vertical flow constrictions is more rapid with increasing discharge than with lateral flow constrictions.

The experimental data from the combined vertical and lateral flow constrictions show an abrupt, but diffuse decrease in $h_{*}$ and $\mathrm{F}_{0}$ as a function of $a_{*} \cdot b_{*}$. The differences of 0.31 in $h_{*}$ and 0.45 in $\mathrm{F}_{0}$ indicate a lower sensitivity of $a_{*} \cdot b_{*}$ with respect to the discharge. The steepness suggests that the vertical constriction is the governing parameter of combined flow constrictions. However, the correlation between the measurement data from the combined constriction is low, which is also reflected in the low coefficients of determination (Table 2). An extension of the measurements with the combined constrictions was not possible because of the model limitations regarding the discharge.

\section{Discharge Capacity of Flow Constrictions}

For the discharge coefficient $\mu$, Leys (1976), Zollinger (1983), and Mejean et al. (2015) propose values within the range of $[0.60,0.70]$. These observations are confirmed by the present experimental data, but only when $h_{*}>0.7$ and $\mathrm{F}_{0}>0.5$, where $\mu=0.69 \pm 0.08$. For important impounding (i.e., $h_{*}<0.7$ and $F_{0}<0.5$ ), the upstream flow conditions significantly influence $\mu$, which should be considered for the design of flow constrictions based on the linear regression curves shown in Fig. 8.

As described previously, Eq. (1) is inappropriate for free surface flow, which occurs for lateral flow constriction only. The approach used by Armanini and Larcher (2001) considers the constriction as a control section. This approach is further developed here for constrictions with a trapezoidal bottom according to Eq. (3) replacing the flow depth with the energy head. The correction coefficient $\epsilon$ [Eq. (4)] considers the losses neglected that occur in 3D flow. By neglecting these losses, it can be expected that $\epsilon$ will be smaller than unity. However, Eq. (3) underestimates the discharge capacity $(\epsilon>1)$. Fig. 9 also indicates a limit value of $b_{*}$ and $\mathbf{F}_{0}$, where $\epsilon$ has a local maximum. This limit value can be associated with ranges of $b_{*}=0.37 \pm 0.03$ or $\mathrm{F}_{0}=0.40 \pm 0.05$.

A comparison of Eqs. (2) and (3) indicates that $\mu=\epsilon / \sqrt{3}$. This analogy is only valid for rectangular cross sections with substantial backwater, which is confirmed by the data shown in Fig. 9. However, based on the data, it is not possible to conclude whether substantial backwater or the constriction geometry (rectangular or trapezoidal) plays a more important role.

Mejean et al. (2015) as well as Piton and Recking (2016a) state that the discharge capacity is underestimated by approximately $11 \%$ when the approach of Armanini and Larcher (2001) is applied for clear water flow. Therefore, Piton and Recking (2016a) 

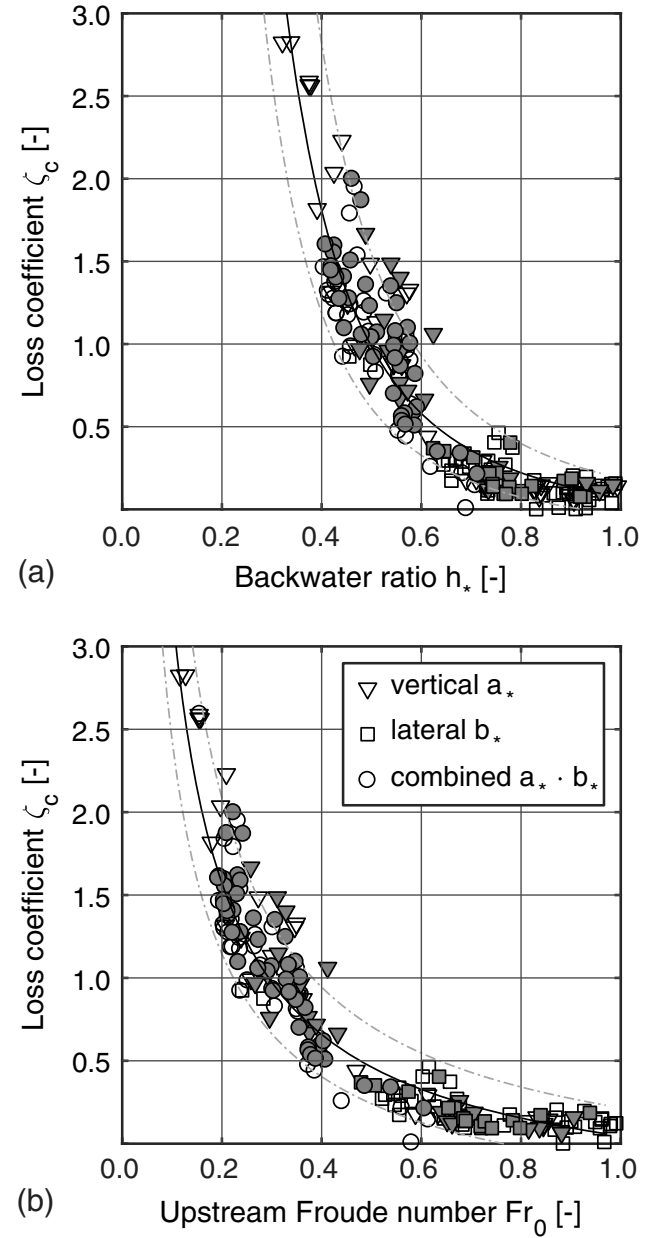

Fig. 7. Experimental values of the loss coefficient $\zeta_{c}$ [Eq. (12)] as a function of (a) the backwater ratio; (b) the upstream Froude number; the regression curves according to Eq. (11) and Table 2 are represented, with indication (dashed lines) of the standard deviation (68\% confidence interval); the filled data points correspond to measurements with bedload recommend applying Eq. (1), simplified for rectangular cross sections, also for free surface flow. Eq. (3) is physically correct for free surface flow, but the evaluation of the correction coefficient $\epsilon$ indicates unequivocal application limits of Eq. (3) for low and high values of $b_{*}$ and $\mathrm{F}_{0}$.

\section{Evaluation of the Effect on the Bedload Transport Capacity}

Only data sets without sediment deposition upstream of the constriction are considered here. However, an effect on the backwater was observed in additional experiments with sediment deposition. Alternatively, the dimensionless bed shear stress related to the hydraulic bedload transport capacity can be derived using the representative sediment grain size $D$ instead of $h_{0, n c}$ in the dimensional analysis (Einstein 1950). This results in the dimensionless critical bed shear stress $\tau_{*}=\tau_{0} /\left[g\left(\rho_{s}-\rho_{f}\right) D\right]$ according to Shields (1936), where $\tau_{*}$ remains unchanged in the rough turbulent flow regime. $\tau_{*}$ varies with the grain mixture, channel roughness, and relative submergence (Wilcock 1993; Recking et al. 2008b; Ferguson 2012). $\tau_{*}$ increases with decreasing relative submergence of the grains $(h / D)$ and with increasing bedload (Gregoretti 2008; Recking et al. 2008a). The flow constriction slows down the flow and increases the relative submergence upstream. Consequently, the maximum sediment transport rate decreases.

Applying $D_{m}$ as the representative grain size, the experiments in the nonconstricted channel result in $\tau_{*} \approx 0.07$. This value is significantly higher than suggested by Shields (1936) but reasonable for moderately steep and rough channels (Prancevic et al. 2014). With the introduction of flow constrictions, the energy slope decreases exponentially, and, therefore, the dimensionless bed shear stress $\tau_{*}$ and its reduction $\eta$ decrease as well. According to the value of $\tau_{*}$ in the nonconstricted channel, bedload transport theoretically ceases when $\eta \leq 0.4\left(\tau_{*} \approx 0.03\right)$, which corresponds to $\mathrm{F}_{0} \approx 0.7$. Small amounts of sediment could still pass even when $F_{0} \ll<0.7$. However, in the context of sediment check dams, these transport rates are negligible. Therefore, the hydraulic obstruction of open sediment check dams occurs for all types of constrictions when $\mathrm{F}_{0} \leq 0.7$.
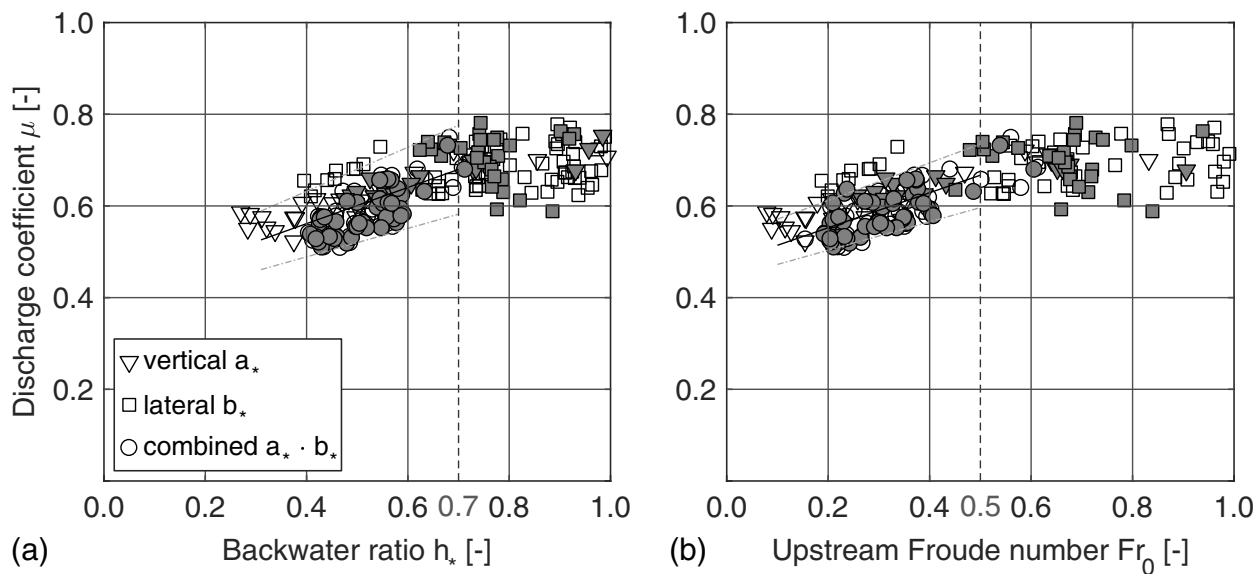

Fig. 8. Experimental values of the discharge coefficient $\mu$ [Eq. (1)] as a function of (a) the backwater ratio; (b) the upstream Froude number; the regression curves according to Eq. (11) and Table 2 are represented for low Froude numbers $(F<0.5)$ with well-developed backwater $\left(h_{*}<0.7\right)$, with indication (dashed lines) of the standard deviation $(68 \%$ confidence interval); the filled data points correspond to measurements with bedload 

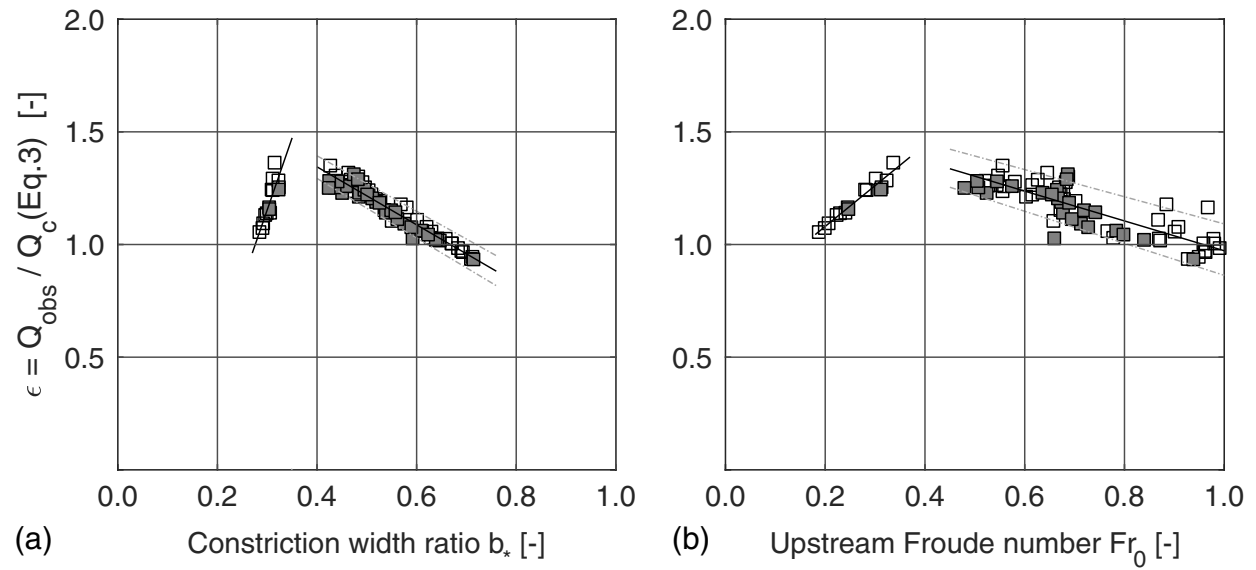

Fig. 9. Ratio $\epsilon$ of the observed and calculated discharge according Eq. (3), as a function of (a) the constriction width ratio $b_{*}$; (b) the upstream Froude number for lateral flow constrictions with free surface flow; the regression curves according to Eq. (11) and Table 2 are represented; the dashed lines indicate the standard deviation (68\% confidence interval); the filled data points correspond to measurements with bedload

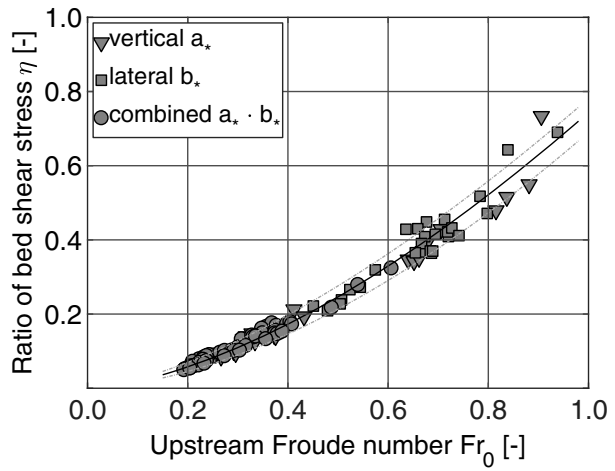

Fig. 10. Ratio of bed shear stress reduction $\eta$ as a function of the upstream Froude number $\mathrm{F}_{0}$; the regression curve according to Eq. (11) and Table 2 is represented, with indication (dashed lines) of the standard deviation ( $68 \%$ confidence interval)

Schwindt et al. (2016) compare the decrease in the absolute bedload transport under capacity conditions as a function of lateral flow constrictions. The authors show that the bedload transport capacity is not influenced by lateral constriction width ratios larger than 0.9 and drops to zero for constriction width ratios less than one-third. These results are in good agreement with the analysis based on the bed shear stress reduction, as shown in Fig. 10.

\section{Application}

Piton and Recking (2016a) present a 13-step design approach for sediment traps, where the opening dimensions of the check dam are based on the upstream deposition height. However, the design criterion for sediment traps in terms of flood protection measures is often based on a certain flood discharge and its related bedload transport capacity that endangers downstream dwellers. This requires hydraulically triggered sediment trapping, which is controlled by the size of the check dam opening.

The following procedure illustrates the application of the results of this study to the design of a check dam opening for a certain flood discharge of $50 \mathrm{~m}^{3} / \mathrm{s}$ at which sediment deposition is targeted. In the following example, the reference channel is characterized by a trapezoidal cross section with an 8-m bottom width, a
$2 \%$ slope, a $28-\mathrm{m}^{1 / 2} / \mathrm{s}$ Chézy coefficient, and a bank inclination of $m=2.4$.

1. The hydraulics of the nonconstricted channel can be determined using the Gauckler-Manning-Strickler formula (Henderson 1966).

For the aforementioned reference channel, the uniform flow depth for a design discharge of $Q=50 \mathrm{~m}^{3} / \mathrm{s}$ is $h_{0, n c} \approx 1.2 \mathrm{~m}$.

2. The hydraulic bedload transport capacity is close to zero when $\eta<0.4$ and $F_{0} \leq 0.7$. The iterative evaluation of the Froude number $\mathrm{F}_{0}=0.7$ results in $h_{0, c} \approx 1.7 \mathrm{~m}$. Thus, the backwater ratio is $h_{*} \approx 0.7$.

3. Three different constriction types can be applied to attain a backwater ratio of $h_{*} \approx 0.7$. Depending on the constriction type, the required dimensions (constriction ratio) can be determined according to Fig. 6(a):

$a$. For a vertical flow constriction, the corresponding constriction height ratio is $a_{*} \approx 0.9$.

Following the aforementioned example, this results in constriction height of $a=0.9 \cdot h_{0, n c} \approx 1.1 \mathrm{~m}$.

$b$. For a lateral flow constriction, the corresponding constriction width ratio is $b_{*}=0.5$.

For the uniform flow depth of $1.2 \mathrm{~m}$, the surface flow width is approximately $13.8 \mathrm{~m}$. Then the required constriction width becomes $b=0.5 \cdot w+2 h_{0, c} m \approx 7 \mathrm{~m}$.

$c$. A combined constriction is not considered here because of the low correlation between the measurements with combined flow constrictions.

For the computation of backwater curves or for the design of downstream structures such as scour protection, the constrictioninduced local energy losses and backwater are also of interest for higher flood discharges. Computing this requires a boundary condition at the constriction considered. According to the findings of the present study, the backwater ratio or the upstream Froude number in close vicinity to the constriction can serve to assess the boundary condition. Based on the previously mentioned design example of a vertical flow constriction for a discharge of $50 \mathrm{~m}^{3} / \mathrm{s}$, the evaluation of the boundary conditions just upstream of a flow constriction and the derivation of related local energy losses for a $10 \%$ higher discharge of $55 \mathrm{~m}^{3} / \mathrm{s}$ can be assessed as follows:

- A stage-discharge relation can be established based on the discharge capacity of the constriction.

Considering the sensitive effects of vertical flow constrictions, substantial backwater is already assumed for a discharge 
of $55 \mathrm{~m}^{3} / \mathrm{s}$; that is, the upstream Froude number is less than 0.5 . Therefore, the discharge coefficient $\mu$ is a linear function of the upstream Froude number. This requires an iterative solution for Eq. (1), and the discharge coefficient $\mu$ according to Fig. 8 with Eq. (11) and coefficients according to Table 2. Here, this results in $\mu\left(55 \mathrm{~m}^{3} / \mathrm{s}\right)=0.50$, and $\mathrm{F}_{0}\left(55 \mathrm{~m}^{3} / \mathrm{s}\right)=0.50$.

- Based on the upstream Froude number $F_{0}$, the local energy losses can be derived according to Eq. (11) and Table 2, that is, $\zeta_{c}\left(\mathrm{~F}_{0}=0.06\right)=0.51 \cdot \mathrm{F}_{0}{ }^{-0.86}-0.46 \approx 5$.

- The related reduction of the bedload transport capacity can be computed according to Fig. 10.

In the example, the bedload transport capacity is close to zero for $\mathrm{F}_{0}=0.06(\eta \approx 0.10)$.

The values assume that no overspill of the open check dam occurs. As this requires a considerable dam height, in practice, overspill may be considered, for example, according to Khatsuria (2005).

\section{Conclusions}

Flow constrictions in open channel flows, by lateral, vertical, or combined constrictions, have been experimentally studied herein for hydraulically controlled obstructions concerning local energy losses, discharge capacity, and bedload transport capacity.

Vertical flow constrictions have a significant influence on the upstream Froude number. The energy loss from the constriction can be estimated by an empirical relationship as a function of the upstream Froude number.

For the computation of the discharge capacity of pressurized flow constrictions, the discharge coefficient $\mu$ must be known. For substantial backwater $\left(F_{0}<0.5\right), \mu$ is linearly increasing with the upstream Froude number. For less significant backwater $\left(F_{0}>\right.$ $0.5), \mu$ is approximately constant with values of $0.69 \pm 0.08$. The tested approach for the discharge capacity of free surface flow conditions in the constriction is bound to some limit value of $F_{0}$.

The influence of bedload transport on the flow depth is negligible for the tested $2 \%$ inclined nonconstricted and constricted channel.

However, the constriction reduces the bedload transport capacity of the flow. This reduction can be assessed by the ratio of the critical bed shear stresses in the constricted and the nonconstricted flow. The ratio of critical bed shear stresses can be empirically predicted when the upstream Froude number is known. In particular, the bedload transport capacity of the channel becomes very low when the Froude number upstream of the constriction is less than 0.7 .

\section{Acknowledgments}

This research is funded by the Swiss Federal Office for the Environment within the Sediment and Habitat Dynamics project. Guillaume Piton (Irstea Grenoble, France) contributed within fruitful discussions to the research.

\section{Notation}

The following symbols are used in this paper:

$A=$ flow cross section $\left(\mathrm{m}^{2}\right)$;

$a=$ constriction height $(\mathrm{m})$;

$a_{*}=$ constriction height ratio;

$b=$ constriction width $(\mathrm{m})$;

$b_{*}=$ constriction width ratio;

$C=$ Chézy roughness coefficient $\left(\mathrm{m}^{1 / 2} \mathrm{~s}^{-1}\right)$;
$D_{m}=$ mean grain diameter of the sediment mixture (m);

$D_{\max }=$ diameter of the largest grain of the sediment mixture (m);

$D=$ grain diameter of the sediment mixture, where $\# \%$ of the mixture is smaller $(\mathrm{m})$;

$E=$ total energy per unit weight $(\mathrm{m})$;

$\mathrm{F}=$ Froude number;

$f=$ function;

$g=$ gravity acceleration $\left(\mathrm{ms}^{-2}\right)$;

$H=$ energy head $(\mathrm{m})$;

$h=$ flow depth, generic (m);

$h_{c}=$ flow depth, constricted channel (m);

$h_{n c}=$ flow depth, nonconstricted channel (m);

$h_{*}=$ backwater ratio;

$J_{e}=$ energy slope;

$J_{0}=$ channel slope;

$m=$ channel bank slope;

$p=$ regression curve coefficient;

$Q=$ water discharge $\left(\mathrm{m}^{3} \mathrm{~s}^{-1}\right)$;

$Q_{b}=$ bedload transport capacity $\left(\mathrm{kg} \mathrm{s}^{-1}\right)$;

$Q_{c}=$ water discharge capacity of flow constrictions $\left(\mathrm{m}^{3} \mathrm{~s}^{-1}\right)$;

$q=$ water discharge per unit width $\left(\mathrm{m}^{2} \mathrm{~s}^{-1}\right)$;

$q_{b}=$ bedload transport capacity per unit width $\left(\mathrm{kg} \mathrm{s}^{-1} \mathrm{~m}^{-1}\right)$;

$R^{2}=$ coefficient of determination;

$R_{h}=$ hydraulic radius $(\mathrm{m})$;

$s=$ specific density of sediment;

$u=$ cross-averaged flow velocity $(\mathrm{m} / \mathrm{s})$;

$w=$ channel bottom width $(\mathrm{m})$;

$\eta=$ ratio of bed shear stress;

$\mu=$ discharge coefficient;

$\epsilon=$ correction factor for the theoretic discharge capacity of a lateral constriction;

$\nu=$ kinematic viscosity $\left(\mathrm{m}^{2} / \mathrm{s}\right)$;

$\Pi=$ expression for dimensionless number;

$\rho_{f}=$ water density $\left(\mathrm{kg} \mathrm{m}^{-3}\right)$;

$\rho_{s}=$ grain density $\left(\mathrm{kg} \mathrm{m}^{-3}\right)$;

$\zeta_{c}=$ energy loss coefficient;

$\tau_{0}=$ bed shear stress $\left(\mathrm{Nm}^{-2}\right)$; and

$\tau_{*}=$ dimensionless bed shear stress.

\section{Subscripts}

$c=$ related to the constricted channel;

$n c=$ related to the nonconstricted channel;

$r=$ roughness;

$0=$ section 0 , upstream of the constriction; and

$1=$ section 1 , downstream of the constriction.

\section{References}

Adams, R. K., and Spotila, J. A. (2005). "The form and function of headwater streams based on field and modeling investigations in the Southern Appalachian Mountains." Earth Surf. Processes Landforms, 30(12), 1521-1546.

Armanini, A., Dalri, C., and Larcher, M. (2006). "Slit-check dams for controlling debris flow and mudflow." Int. Symp. on Disaster Mitigation of Debris Flows, Slope Failures and Landslides, Universal Academy Press, Inc., Niigata, Japan, 141-148.

Armanini, A., Dellagiacoma, F., and Ferrari, L. (1991). "From the check dam to the development of functional check dams." Fluvial hydraulics of mountain regions, Springer, Berlin, 331-344. 
Armanini, A., and Larcher, M. (2001). "Rational criterion for designing opening of slit-check dam." J. Hydraul. Eng., 10.1061/(ASCE)07339429(2001)127:2(94), 94-104.

Barenblatt, G. I. (1987). Dimensional analysis, Gordon and Breach Science Publishers, New York.

Benda, L. (1990). "The influence of debris flows on channels and valley floors in the Oregon coast range, U.S.A." Earth Surf. Processes Landforms, 15(5), 457-466.

Beschta, R. L. (1979). "Debris removal and its effects on sedimentation in an Oregon Coast Range stream.” Northwest Sci., 53(1), 71-77.

Bezzola, G. R., and Hegg, C. (2007). Ereignisanalyse Hochwasser 2005, Teil 1-Prozesse, Schäden und erste Einordnung [Event analyses of the 2005 flood. 1: Processes, damages and preliminary classification], Swiss Federal Office for the Environment FOEN/Eidgenössische Forschungsanstalt WSL, Bern, Switzerland.

Brooke Benjamin, T. (1956). "On the flow in channels when rigid obstacles are placed in the stream." J. Fluid Mech., 1(2), 227-248.

Chapra, S. C., and Canale, R. P. (2010). Numerical methods for engineers, 6th Ed., McGraw-Hill, New York.

Chow, V. T. (1959). Open-channel hydraulics, McGraw-Hill, Tokyo.

Davies, P., et al. (2005). "Changes to headwater stream morphology, habitats and riparian vegetation recorded 15 years after pre-forest practices code forest clearfelling in upland granite terrain, Tasmania, Australia." For. Ecol. Manage., 217(2-3), 331-350.

Einstein, H. A. (1950). "The bed-load function for sediment transport in open channel flows." Technical Bulletin No. 1026, U.S. Dept. of Agriculture, Soil Conservation Service, Quilcene, WA, 71.

Ferguson, R. I. (2010). "Time to abandon the manning equation?" Earth Surf. Processes Landforms, 35(15), 1873-1876.

Ferguson, R. I. (2012). "River channel slope, flow resistance, and gravel entrainment thresholds." Water Resour. Res., 48(5), 1-13.

Frey, P., Tannou, S., Tacnet, J., Richard, D., and Koulinski, V. (1999). Interactions Ecoulements torrentiels-Ouvrages terminaux de plages de dépôt [Interactions between torrential flows and open check dams], Pôle grenoblois d'Etudes et de Recherche pour la prévention des risques naturels, Grenoble, France.

Gertsch, E. (2009). "Geschiebelieferung alpiner Wildbachsysteme bei Grossereignissen-Ereignis analysen und Entwicklung eines Abschätzverfahrens." Ph.D. thesis, Geographisches Institut der Universität Bern, Bern, Switzerland.

Gomi, T., Sidle, R. C., and Richardson, J. S. (2002). "Understanding processes and downstream linkages of headwater systems." BioScience, 52(10), 905-916.

Gregoretti, C. (2008). "Inception sediment transport relationships at high slopes.” J. Hydraul. Eng., 10.1061/(ASCE)0733-9429(2008) 134:11(1620), 1620-1629.

Hassan, M. A., Church, M., Lisle, T. E., Brardinoni, F., Benda, L., and Grant, G. E. (2005). "Sediment transport and channel morphology of small, forested streams." J. Am. Water Resour. Assoc., 41(4), 853-876.

Henderson, F. M. (1966). Open channel flow, The Macmillan Company, New York.

Khatsuria, R. (2005). Hydraulics of spillways and energy dissipaters, Marcel Dekker, New York, 635.

Kondolf, G. M. (1997). "Hungry water: Effects of dams and gravel mining on river channels." Environ. Manage., 21(4), 533-551.

Lange, D., and Bezzola, G. R. (2006). Schwemmholz Probleme und Lösungansätze [Driftwood problems and approaches for solutions], Vol. 188, Mitteilungen der Versuchsanstalt für Wasserbau, Hydrologie und Glaziologie an der Eidgenössischen Technischen Hochschule Zürich, Zürich, Switzerland.

Leopold, L. B., and Wolman, M. G. (1957). "River channel patterns: Braided meandering and straight." USGS Professional Paper, 282-B, U.S. Government Printing Office, Washington, DC, 45-62.

LeRoy, N., et al. (1997). "The natural flow regime-A paradigm for river conservation and restoration." BioScience, 47(11), 769-784.

Leys, E. (1976). "Die technischen und wirtschaftlichen Grundlagen in der Wildbachverbauung der groß doligen und der kronenoffenen Bauweise [Technical and economical basics of hydraulic constructions in mountain rivers in terms of large openings and open crested architecture]." Ph.D. thesis, Universität für Bodenkultur, Vienna, Austria.

McEnroe, B. M. (2009). "Hydrologic design of bridges and culverts: A historical review." World Environmental and Water Resources Congress, Great Rivers History, ASCE, Reston, VA, 83-90.

Mejean, S., Piton, G., and Recking, A. (2015). Caractérisation des conditions hydrauliques du piégeage de la charge sédimentaire grossière des torrents [Characterization of hydraulic conditions for the trapping of the coarse sediment load of torrents], Erosion torrentielle neige et avalanche Grenoble, IRSTEA, Grenoble, France, 90.

Montgomery, D. R., Abbe, T. B., Buffington, J. M., Peterson, N. P., Schmidt, K. M., and Stock, J. D. (1996). "Distribution of bedrock and alluvial channels in forested mountain drainage basins." Nature, 381(6583), 587-589.

Montgomery, D. R., and Buffington, J. (1997). "Channel-reach morphology in mountain drainage basins." Geol. Soc. Am. Bull., 109(5), 596-611.

Parker, G., Paola, C., Whipple, K. X., and Mohrig, D. (1998). "Alluvial fans formed by channelized fluvial and sheet flow. I: Theory." J. Hydraul. Eng., 10.1061/(ASCE)0733-9429(1998)124:10(985), 985-995.

Piton, G., et al. (2017). "Why do we build check dams in Alpine streams? An historical perspective from the French experience." Earth Surf. Processes Landforms, 42(1), 91-108.

Piton, G., and Recking, A. (2016a). "Design of sediment traps with open check dams. I: Hydraulic and deposition processes." J. Hydraul. Eng., 10.1061/(ASCE)HY.1943-7900.0001048, 04015045.

Piton, G., and Recking, A. (2016b). "Design of sediment traps with open check dams. II: Woody debris." J. Hydraul. Eng., 142(2), 04015046.

Powell, M. D. (2014). "Flow resistance in gravel-bed rivers: Progress in research.” Earth Sci. Rev., 136, 301-338.

Prancevic, J. P., Lamb, M. P., and Fuller, B. M. (2014). "Incipient sediment motion across the river to debris-flow transition." Geology, 42(3), 191-194.

Recking, A. (2010). "A comparison between flume and field bedload transport data and consequences for surface-based bedload transport prediction." Water Resour. Res., 46(3), W03518.

Recking, A. (2012). "Influence of sediment supply on mountain streams bedload transport." Geomorphology, 175-176, 139-150.

Recking, A., Frey, P., Paquier, A., Belleudy, P., and Champagne, J. Y. (2008a). "Bed-load transport flume experiments on steep slopes." J. Hydraul. Eng., 10.1061/(ASCE)0733-9429(2008)134:9(1302), 1302-1310.

Recking, A., Frey, P., Paquier, A., Belleudy, P., and Champagne, J. Y. (2008b). "Feedback between bed load transport and flow resistance in gravel and cobble bed rivers." Water Resour. Res., 44(5), W05412.

Sawada, T., Ashida, K., and Takahashi, T. (1983). "Relationship between channel pattern and sediment transport in a steep gravel bed river." Zeitschrift für Geomorphologie, Supplementband, 46, 55-66.

Schleiss, A. J., et al. (2014). "Geschiebe- und HabitatsdynamikForschungsprogramm Wasserbau und Ökologie [The research program sediment and habitat dynamics]." Wasser Energie Luft, 106(2), $117-122$.

Schwindt, S., Franca, M. J., and Schleiss, A. J. (2016). "The influence of the opening width of check dams on bedload continuity of mountain rivers." River Flow 2016, G. Constantinescu, M. Garcia, and D. Hanes, eds., Tayler \& Francis, St. Louis, 1156-1160.

Shields, A. (1936). Anwendung der Ähnlichkeitsmechanik und der Turbulenzforschung auf die Geschiebebewegung [Application of the similarity in mechanics and turbulence research on the mobility of bed load], Vol. 26, Preußische Versuchsanstalt für Wasserbau und Schiffbau, Berlin.

Smart, G. M., and Jaeggi, M. N. R. (1983). Sedimenttransport in steilen Gerinnen [Sediment transport on steep slopes], Vol. 64, Mitteilungen der Versuchsanstalt für Wasserbau, Hydrologie und Glaziologie an der Eidgenössischen Technischen Hochschule Zürich, Zürich, Switzerland.

Sutherland, D. G., Hansler Ball, M., Hilton, S., and Lisle, T. E. (2002). "Evolution of a landslide-induced sediment wave in the Navarro River, California." Geol. Soc. Am. Bull., 114(8), 1036-1048. 
Uchiogi, T., Shima, J., Tajima, H., and Ishikawa, Y. (1996). "Design methods for wood-debris entrapment." Proc., INTERPRAEVENT, Vol. 5, International Research Society Interpraevent, Klagenfurt, Austria, 279-288.

Von Mises, R. (1917). "Berechnung von Ausfluss- und Ueberfallzahlen [Computation of discharge coefficients]." Zeitschrift des Vereins deutscher Ingenieure, 61(22), 447-452.

Werner, W. (1963). "Ableitung einer kinematischen Beziehung zur Berechnung des Durchflusses unter Planschützen nach der Theorie freier Stromlinien [Derivation of a kinematic relation for the computation of the discharge under sluice gates according to the theory of free streamlines]." Wissenschaftliche Zeitschrift der Technischen Universität Dresden, 12(6), 1693-1699.
Whittaker, J. G. (1987). "Sediment transport in step-pool streams." Sediment transport in gravel bed rivers, C. R. Thorne, J. C. Bathurst, and R. D. Hey, eds., Wiley, Chichester, U.K.

Wilcock, P. (1993). "Critical shear stress of natural sediments." J. Hydraul. Eng., 10.1061/(ASCE)0733-9429(1993)119:4(491), 491-505.

Williams, G. P., and Wolman, M. G. (1984). "Downstream effects of dams on alluvial rivers." Geological Survey Professional 1286, U.S. Government Printing Office, Washington, DC.

Zollinger, F. (1983). Die Vorgänge in einem Geschiebeablagerungsplatz: ihre Morphologie und ihre Möglichkeiten einer Steuerung [The processes in sediment traps: Their morphology and their possibilities of control], ETH Zürich, Zürich, Switzerland. 